\title{
Public Perception of the Attitude of Drivers on Abuja Roads
}

\author{
Faith A. Obafemi ${ }^{1}$, Sam B. Obafemi ${ }^{2}$ \\ ${ }^{1}$ Department of Physiology, Faculty of Veterinary Medicine, University of Abuja, Abuja, Nigeria \\ ${ }^{2}$ Sam Obafemi Behavioural Change Academy (SOBCA), Abuja, Nigeria \\ Email: faithoba@ymail.com, boostsfromfaith@gmail.com
}

How to cite this paper: Obafemi, F. A., \& Obafemi, S. B. (2021). Public Perception of the Attitude of Drivers on Abuja Roads. Psychology, 12, 2070-2082.

https://doi.org/10.4236/psych.2021.1212125

Received: June 12, 2021

Accepted: December 28, 2021

Published: December 31, 2021

Copyright (c) 2021 by author(s) and Scientific Research Publishing Inc. This work is licensed under the Creative Commons Attribution International License (CC BY 4.0).

http://creativecommons.org/licenses/by/4.0/ (c) (i) Open Access

\begin{abstract}
The increasing prevalence of road traffic crashes and the involvement of high casualties are becoming a major public health concern which needs to be tackled urgently. This urgency is of particular importance in developing nations. To address the pressing challenge, there is a need to study the factors necessitating driver behaviour, hence the aim of the current study. The current study has two components: the first is to test the public's perception of drivers' attitudes in Abuja, the Federal Capital Territory, and the second is to assess common driving behaviours that have been identified as causes of crash. The study adopted the cross-sectional design with the study area purposively selected and questionnaires were distributed randomly to eighty (80) participants in the Municipal Area Council of the FCT. Results indicating respondents' perception of drivers' attitude showed that $38.8 \%$ of drivers are mostly reckless, $27.5 \%$ are inpatient, $10 \%$ are indecent, $2.5 \%$ are aggressive. Participants indicated that these attitudes could come from driver's aggression $(76.3 \%)$. This study was able to identify rage as one of the key contributors to attitudinal adjustment in drivers, establishing a relation between driver attitude and road traffic accidents. Impatience, stress, incompetence, desperation, lack of discipline, and irritability were also recognized as important indications of driver overall attitudinal difficulties in the research area. It is recommended that intervention to improve emotional control be designed in order to essentially bring about a shift towards proper driving attitude. It can be stipulated that non-professional as well as professional drivers receive regular emotional management training as part of their license renewal program.
\end{abstract}

\section{Keywords}

Drive, Attitude, Perception, Road 


\section{Introduction}

Road traffic accidents happen all over the world. However, in comparison to developed countries, the frequency of these crashes is higher in developing countries. According to global estimates, road traffic crashes claim the lives of approximately 1.35 million people each year, with an additional 20 to 50 million people suffering non-fatal injuries, many of which result in various forms of disability (International Transport Forum, 2020).

Road traffic injuries are one of the leading causes of death and injury, according to the World Health Organization (World Health Organization, 2015). The number of road traffic injuries has been increasing in Africa. Africa has $2 \%$ of the world's cars but $20 \%$ of the world's road deaths (World Health Organization, 2015). According to the Federal Road Safety Commission (FRSC, 2017), 5053 people were killed in 9694 road crashes in 2016, a decrease of 387 people when compared to the death toll of 5440 in 2015, when 9734 crashes occurred.

According to Ukoji (2014), unsafe driving behaviours account for up to $90 \%$ of crashes in Nigeria, including inappropriate speeding and speed-related factors, a lack of understanding of traffic regulations, including road signs and markings, drink driving, dangerous driving, driver fatigue, and inappropriate overtaking. Individuals' quality of life, social and economic activities and the nation's overall economic activity are all affected by crashes, according to Gudaji and Dankishiya (2016). Traffic accidents have been linked to human, mechanical, and environmental elements in studies (Odufuwa et al., 2017). Indeed, the human component, which is the subject of this study, encompasses a wide range of driver characteristics, including age, medical fitness, mental health, alcohol intake, and educational level, among others (Eiksund, 2009).

According to $\mathrm{Qu}$ et al. (2014), driver's abnormal driving habits appear to be greater and more direct predictors of road crash risk than driving anger. Risky and aggressive driving behaviours, such as speeding or running red lights, accounted for nearly $94.4 \%$ of all road deaths in China (Qu et al., 2014). It's been proven that driving rage and erratic driving habits are linked (Zhang \& Chan, 2016). Anger has been shown to interfere with human cognitive functions such as attention (Schimmack \& Derryberry, 2005) and judgment (Evans, 2008), leading to exaggerated optimism and poor danger perception in angry people. As a result, drivers who have expressed a higher level of rage on the road are more likely to commit traffic offences (such as tailgating and speeding) (Abdu et al., 2012). There have been various studies on the relationship between driving rage and driving errors. The majority of research has indicated a positive link (Berdoulat et al., 2013), whereas a few have found no link (Gonzalez-Iglesias et al., 2012; Berdoulat et al., 2013). Recent data reveals, however, that the anger-aberration relationship is more complicated than a straightforward positive correlation (Zhang et al., 2015).

The purpose of this study was to determine the public's perception of drivers' attitude on the road. The study took advantage of a population that drives on a 
regular basis but not necessarily on a permanent basis. The current study has two components: the first is to test the public's perception of drivers' attitudes in Abuja, the Federal Capital Territory, and the second is to assess common driving behaviors that have been identified as crash causes in literature.

\section{Materials and Methods}

\subsection{Study Area}

Abuja Municipal Area Council is the largest and most developed of the six area Councils in the Federal Capital Territory (FCT). The bulk of the Area Council is made up of the Federal Capital City which has five districts; Asokoro, Maitama, Garki, Wuse, and Central Area as well as newly developed districts Apo, Gaduwa, Gudu, Lokugoma, Kaura, Durumi, Katampe, Gwarimpa (Federal Government of Nigeria Official Gazette, 2007). Abuja Municipal Area Council is located between latitude $8^{\circ} 40$ and $9^{\circ} 20$ North of the equator and longitude $6^{\circ} 40$ and $7^{\circ} 40$ East of the Greenwich meridian. Abuja's metro area held a population of 3,095,000 as of 2019 and is currently estimated to have increased by $5.91 \%$ giving rise to a population of $3,278,000$ in 2020 .

\subsection{Sampling}

The current study is a cross sectional study. Sampling was done purposively; the Abuja Municipal Area Council was selected purposively due to the high levels of activity in the area council. Seven (7) out of the 13 districts were selected randomly for sampling. The questionnaires were distributed randomly and the aim of the study described to the respondents before they filled the questionnaire.

\subsection{Data Collection}

Data collection was done with a pre-tested, structured, interviewer-administered questionnaire. The questionnaire was divided into sections and elicited information on the participants' demography, professional driving experience, frequency of driving and their perception of the attitude of drivers in Abuja.

\subsection{Data Analysis}

Data were analysed with Statistical Package for Social Sciences (version 23). Frequency distribution of variables and cross-tabulation of variables were recorded. A Chi-square test was done to test for association between variables and the level of significance was set at $5 \%$ at a $95 \%$ Confidence Interval.

\section{Result}

\subsection{Socio-Demographic Characteristics}

The socio-demographic features of participants show that females $(52.5 \% ; \mathrm{n}=$ 42) outnumber males $(47.5 \% ; \mathrm{n}=39)$. The age group $31-40$ years $(50.0 \% ; \mathrm{n}=$ 40) had the most participants, followed by $41-50$ years $(26.3 \% ; \mathrm{n}=21), 20-30$ years $(15.0 \% ; \mathrm{n}=12), 51-60$ years $(7.5 \% ; \mathrm{n}=6)$, and $>60(1.3 \% ; \mathrm{n}=1)$. 
According to the descriptive analysis of the participants' educational levels, 1.3\% had obtained a National Diploma (ND), 3.8\% had obtained a Higher National Diploma (HND), $42.5 \%$ had obtained a Bachelor's Degree, $47.5 \%$ had obtained a Postgraduate Degree, and $2.5 \%$ were undergraduates while $2.5 \%$ had obtained their SSCE.

An examination of the participants' occupations revealed that $26.3 \%$ work in the commercial sector, $41.3 \%$ work in the public sector, $28.8 \%$ are entrepreneurs, and $3.8 \%$ are students. In the current study, $93.8 \%(n=75)$ of the 80 participants claimed that they can drive. Analysis of participants' driving experience revealed that $1.3 \%$ had less than one year of driving experience, $15.0 \%$ had between one and five years of driving experience, $21.3 \%$ had between six and ten years of driving experience, $17.5 \%$ had between eleven and fifteen years of driving experience, $15.0 \%$ had between sixteen and twenty years of driving experience, and 23.8\% had more than twenty years of driving experience.

When asked how they learned to drive, $27.4 \%$ said they were taught by a family member, $33.8 \%$ went to a driving school, $17.5 \%$ were self-taught, $6.3 \%$ learned from friends, and $8.8 \%$ were taught by drivers. $75 \%$ of these people said they drive every day, $11.3 \%$ drive every other day, $6.3 \%$ rarely drive, and $1.3 \%$ drive weekly.

\subsection{Test of Association}

Pearson's Chi-Square was used to determine the relationship between variables in the current study. The association test revealed no significant $(p>0.05)$ relationship between gender, driving, driving experience, driving frequency, and learning to drive (Table 1$)$. There was a significant $(p<0.05)$ relationship between the level of education and participant ability to drive, as evidenced by the fact that $100 \%$ of participants with OND, HND, and Postgraduate could drive; 94.1\% of participants with Bachelor's degree could drive; $50 \%$ of undergraduate students could also drive, and $100 \%$ of participants with SSCE could not drive (Table 2). There was, however, no significant $(p>0.05)$ association between level of education and driving experience. There was a significant $(p<0.05)$ association between profession and the ability of respondents to drive. There also existed a significant $(p<0.05)$ association between level of education and frequency of driving (Table 2).

\subsection{Perception of Respondents of Abuja Drivers}

Respondents in the current study described Abuja drivers' attitude to range from reckless to hilarious. $38.8 \%$ of the respondents indicated that Abuja drivers are mostly reckless, $27.5 \%$ believe that they are just inpatient, $10 \%$ indicated that they are indecent, $2.5 \%$ said Abuja drivers are aggressive, $6.3 \%$ indicated that Abuja drivers are fairly decent and $1.3 \%$ think they are hilarious (Table 3). Participants indicated that these attitudes could come from driver's aggression (76.3\%). 
Table 1. Association between driving, age and gender.

\begin{tabular}{|c|c|c|c|c|c|c|c|c|c|}
\hline \multirow{2}{*}{ Questions } & \multicolumn{2}{|c|}{ Gender } & \multirow{2}{*}{$\chi^{2}($ sig) } & \multicolumn{5}{|c|}{ Age } & \multirow{2}{*}{$\chi^{2}($ sig) } \\
\hline & Male & Female & & $20-30$ & $31-40$ & $41-50$ & $51-60$ & $>60$ & \\
\hline Can you drive? & & & $2.259(0.133)$ & & & & & & $1.453(0.835)$ \\
\hline Yes & $34(89.5)$ & $41(97.6)$ & & $11(91.7)$ & $38(95.0)$ & $20(95.2)$ & $5(83.3)$ & $1(100.0)$ & \\
\hline No & $4(10.5)$ & $1(2.4)$ & & $1(8.3)$ & $2(5.0)$ & $1(4.8)$ & $1(16.7)$ & $0(0.0)$ & \\
\hline Total & $38(100.0)$ & $42(10.0)$ & & $12(100.0)$ & $40(100.0)$ & $21(100.0)$ & $6(100.0)$ & $1(100.0)$ & \\
\hline Driving Experience & & & $4.730(0.450)$ & & & & & & $42.302(0.003)$ \\
\hline$<1$ & $1(2.9)$ & $0(0.0)$ & & $0(0.0)$ & $0(0.0)$ & $1(5.0)$ & $0(0.0)$ & $0(0.0)$ & \\
\hline $1-5$ & $4(11.8)$ & $12(16.0)$ & & $3(27.3)$ & $7(18.4)$ & $2(10.0)$ & $0(0.0)$ & $1(100.0)$ & \\
\hline $5-10$ & $8(23.5)$ & $17(22.7)$ & & $6(54.5)$ & $9(23.7)$ & $1(5.0)$ & $0(0.0)$ & $0(0.0)$ & \\
\hline $11-15$ & $9(26.5)$ & $14(18.7)$ & & $1(9.1)$ & $11(28.9)$ & $2(10.0)$ & $0(0.0)$ & $0(0.0)$ & \\
\hline $16-20$ & $4(11.8)$ & $12(16.0)$ & & $1(9.1)$ & $5(13.2)$ & $6(30.0)$ & $0(0.0)$ & $0(0.0)$ & \\
\hline$>20$ & $8(23.5)$ & $19(25.3)$ & & $0(0.0)$ & $6(15.8)$ & $8(40.0)$ & $5(100.0)$ & $0(0.0)$ & \\
\hline Total & $34(100.0)$ & $41(10.0)$ & & & & & & & \\
\hline \multicolumn{3}{|c|}{ How did you learn how to drive? } & $5.019(0.285)$ & & & & & & $13.150(0.662)$ \\
\hline Family member & $11(32.4)$ & $11(26.8)$ & & $4(36.4)$ & $10(26.3)$ & $7(35.0)$ & $1(20.0)$ & $0(0.0)$ & \\
\hline Driving School & $9(26.5)$ & $18(43.9)$ & & $3(27.3)$ & $12(31.6)$ & $8(40.0)$ & $3(60.0)$ & $1(100.0)$ & \\
\hline Self-taught & $9(26.5)$ & $5(12.2)$ & & $0(0.0)$ & $9(23.7)$ & $4(20.0)$ & $1(20.0)$ & $0(0.0)$ & \\
\hline A friend & $3(8.8)$ & $2(4.9)$ & & $1(9.1)$ & $3(7.9)$ & $1(5.0)$ & $0(0.0)$ & $0(0.0)$ & \\
\hline Driver & $2(5.9)$ & $5(12.2)$ & & $3(27.3)$ & $4(10.5)$ & $0(0.0)$ & $0(0.0)$ & $0(0.0)$ & \\
\hline Total & $34(100.0)$ & $41(100.0)$ & & & & & & & \\
\hline \multicolumn{3}{|c|}{ How often do you drive? } & $2.349(0.504)$ & & & & & & $6.169(0.907)$ \\
\hline Daily & $29(85.3)$ & $31(75.6)$ & & $10(90.9)$ & $31(81.6)$ & $15(75.0)$ & $3(60.0)$ & $1(100.0)$ & \\
\hline Every other Day & $4(11.8)$ & $5(12.2)$ & & $0(0.0)$ & $5(13.2)$ & $3(15.0)$ & $1(20.0)$ & $0(0.0)$ & \\
\hline Rarely & $1(2.9)$ & $4(9.8)$ & & $1(9.10)$ & $1(2.6)$ & $2(10.0)$ & $1(20.0)$ & $0(0.0)$ & \\
\hline Weekly & $0(0.0)$ & $1(2.4)$ & & $0(0.0)$ & $1(2.6)$ & $0(0.0)$ & $0(0.0)$ & $0(0.0)$ & \\
\hline \multicolumn{3}{|c|}{ How will you describe Abuja Drivers? } & $6.368(0.383)$ & & & & & & $16.579(0.866)$ \\
\hline Reckless & $13(39.4)$ & $18(47.4)$ & & $4(36.4)$ & $12(32.4)$ & $12(70.6)$ & $3(60.0)$ & $0(0.0)$ & \\
\hline Inpatient & $10(30.3)$ & $12(31.6)$ & & $3(27.3)$ & $14(37.8)$ & $3(17.6)$ & $1(20.0)$ & $1(100.0)$ & \\
\hline Indecent & $3(9.1)$ & $5(7.0)$ & & $2(18.2)$ & $4(10.8)$ & $1(5.9)$ & $1(20.0)$ & $0(0.0)$ & \\
\hline Fairly decent & $2(6.1)$ & $3(7.9)$ & & $2(18.2)$ & $2(5.4)$ & $1(5.9)$ & $0(0.0)$ & $0(0.0)$ & \\
\hline Average & $2(6.1)$ & $0(0.0)$ & & $0(0.0)$ & $2(5.4)$ & $0(0.0)$ & $0(0.0)$ & $0(0.0)$ & \\
\hline Aggressive & $2(6.1)$ & $0(0.0)$ & & $0(0.0)$ & $2(5.4)$ & $0(0.0)$ & $0(0.0)$ & $0(0.0)$ & \\
\hline Hilarious & $1(3.0)$ & $0(0.0)$ & & $0(0.0)$ & $1(2.7)$ & $0(0.0)$ & $0(0.0)$ & $0(0.0)$ & \\
\hline \multicolumn{3}{|c|}{$\begin{array}{l}\text { Do you think Abuja drivers are angry or } \\
\text { aggressive? }\end{array}$} & $1.080(0.431)$ & & & & & & $3.376(0.497)$ \\
\hline Yes & $27(71.1)$ & $34(81.0)$ & & $10(83.3)$ & $28(70.0)$ & $16(76.2)$ & $6(100.0)$ & $1(100.0)$ & \\
\hline
\end{tabular}


Continued

\begin{tabular}{|c|c|c|c|c|c|c|c|c|c|}
\hline No & $11(28.0)$ & $8(19.0)$ & & $2(16.7)$ & $12(30.0)$ & $5(23.8)$ & $0(0.0)$ & $0(0.0)$ & \\
\hline \multicolumn{3}{|c|}{$\begin{array}{l}\text { If yes, what do you think is responsible for } \\
\text { their anger? }\end{array}$} & $4.745(0.577)$ & & & & & & 25.207 (0.119) \\
\hline Don't Know & $1(3.8)$ & $2(6.7)$ & & $0(0.0)$ & $3(9.4)$ & $0(0.0)$ & $0(0.0)$ & $3(5.4)$ & \\
\hline Easily irritated & $3(11.5)$ & $5(16.7)$ & & $2(25.0)$ & $3(9.4)$ & $2(16.7)$ & $1(25.0)$ & $8(14.3)$ & \\
\hline Inpatient & $4(15.4)$ & $10(33.3)$ & & $2(25.0)$ & $9(28.1)$ & $3(25.0)$ & $0(0.0)$ & $14(25.0)$ & \\
\hline Stress & $6(23.1)$ & $5(16.7)$ & & $3(37.5)$ & $7(21.9)$ & $1(8.3)$ & $0(0.0)$ & $11(19.6)$ & \\
\hline Incompetence & $6(23.1)$ & $4(13.3)$ & & $1(12.5)$ & $2(6.3)$ & $5(41.7)$ & $2(50.0)$ & $10(17.9)$ & \\
\hline Desperation & $5(19.2)$ & $4(13.3)$ & & $0(0.0)$ & $8(25.0)$ & $0(0.0)$ & $1(25.0)$ & $9(16.1)$ & \\
\hline Lack of discipline & $1(3.8)$ & $0(0.0)$ & & $0(0.0)$ & $0(0.0)$ & $1(8.3)$ & $0(0.0)$ & $1(1.8)$ & \\
\hline \multicolumn{3}{|c|}{$\begin{array}{l}\text { Do you think this anger problem can be } \\
\text { solved? }\end{array}$} & $0.916(0.525)$ & & & & & & $10.013(0.908)$ \\
\hline Yes & $38(100.0)$ & $0(0.0)$ & & $12(100.0)$ & $39(97.5)$ & $21(100.0)$ & $6(100.0)$ & $1(100.0)$ & \\
\hline No & $41(98.8)$ & $1(2.4)$ & & $0(0.0)$ & $1(2.5)$ & $0(0.0)$ & $0(0.0)$ & $0(0.0)$ & \\
\hline
\end{tabular}

Table 2. Association between driving, and level of education.

\begin{tabular}{|c|c|c|c|c|c|c|c|}
\hline \multirow[b]{2}{*}{ Questions } & \multicolumn{6}{|c|}{ Level of Education } & \multirow[b]{2}{*}{$\chi^{2}$ (sig) } \\
\hline & OND & HND & Degree & $\begin{array}{c}\text { P. } \\
\text { Graduate }\end{array}$ & SSCE & Undergraduate & \\
\hline Can you drive? & & & & & & & $39.341(0.002)$ \\
\hline Yes & $1(100.0)$ & $3(100.0)$ & $32(94.1)$ & $38(100.0)$ & $0(0.0)$ & $1(50.0)$ & \\
\hline No & $0(0.0)$ & $0(0.0)$ & $2(5.9)$ & $0(0.0)$ & $2(100.0)$ & $1(50.0)$ & \\
\hline Driving Experience & & & & & & & $17.370(0.629)$ \\
\hline$<1$ & $0(0.0)$ & $0(0.0)$ & $1(3.1)$ & $0(0.0)$ & $0(0.0)$ & $1(1.3)$ & \\
\hline $1-5$ & $0(0.0)$ & $1(33.3)$ & $5(15.6)$ & $5(13.2)$ & $1(100.0)$ & $12(16.0)$ & \\
\hline $5-10$ & $1(100.0)$ & $0(0.0)$ & $8(25,0)$ & $8(21.1)$ & $0(0.0)$ & $17(22.7)$ & \\
\hline $11-15$ & $0(0.0)$ & $0(0.0)$ & $6(18.8)$ & $8(21.1)$ & $0(0.0)$ & $14(18.7)$ & \\
\hline $16-20$ & $0(0.0)$ & $0(0.0)$ & $3(9.4)$ & $9(23.7)$ & $0(0.0)$ & $12(16.0)$ & \\
\hline$>20$ & $0(0.0)$ & $2(66.7)$ & $9(28.1)$ & $8(21.1)$ & $0(0.0)$ & $19(25.3)$ & \\
\hline \multicolumn{8}{|l|}{ Total } \\
\hline How did you learn how to drive? & & & & & & & $15.160(0.513)$ \\
\hline Family member & $1(100.0)$ & $3(100.0)$ & $7(21.9)$ & $10(26.3)$ & $1(100.0)$ & $22(29.3)$ & \\
\hline Driving School & $0(0.0)$ & $0(0.0)$ & $12(37.5)$ & $15(39.5)$ & $0(0.0)$ & $27(36.0)$ & \\
\hline Self-taught & $0(0.0)$ & $0(0.0)$ & $8(25.0)$ & $6(15.8)$ & $0(0.0)$ & $14(1.7)$ & \\
\hline A friend & $0(0.0)$ & $0(0.0)$ & $3(9.4)$ & $2(5.3)$ & $0(0.0)$ & $5(6.7)$ & \\
\hline Driver & $0(0.0)$ & $0(0.0)$ & $2(6.3)$ & $5(13.3)$ & $0(0.0)$ & $7(9.3)$ & \\
\hline Total & & & & & & & \\
\hline
\end{tabular}


Continued

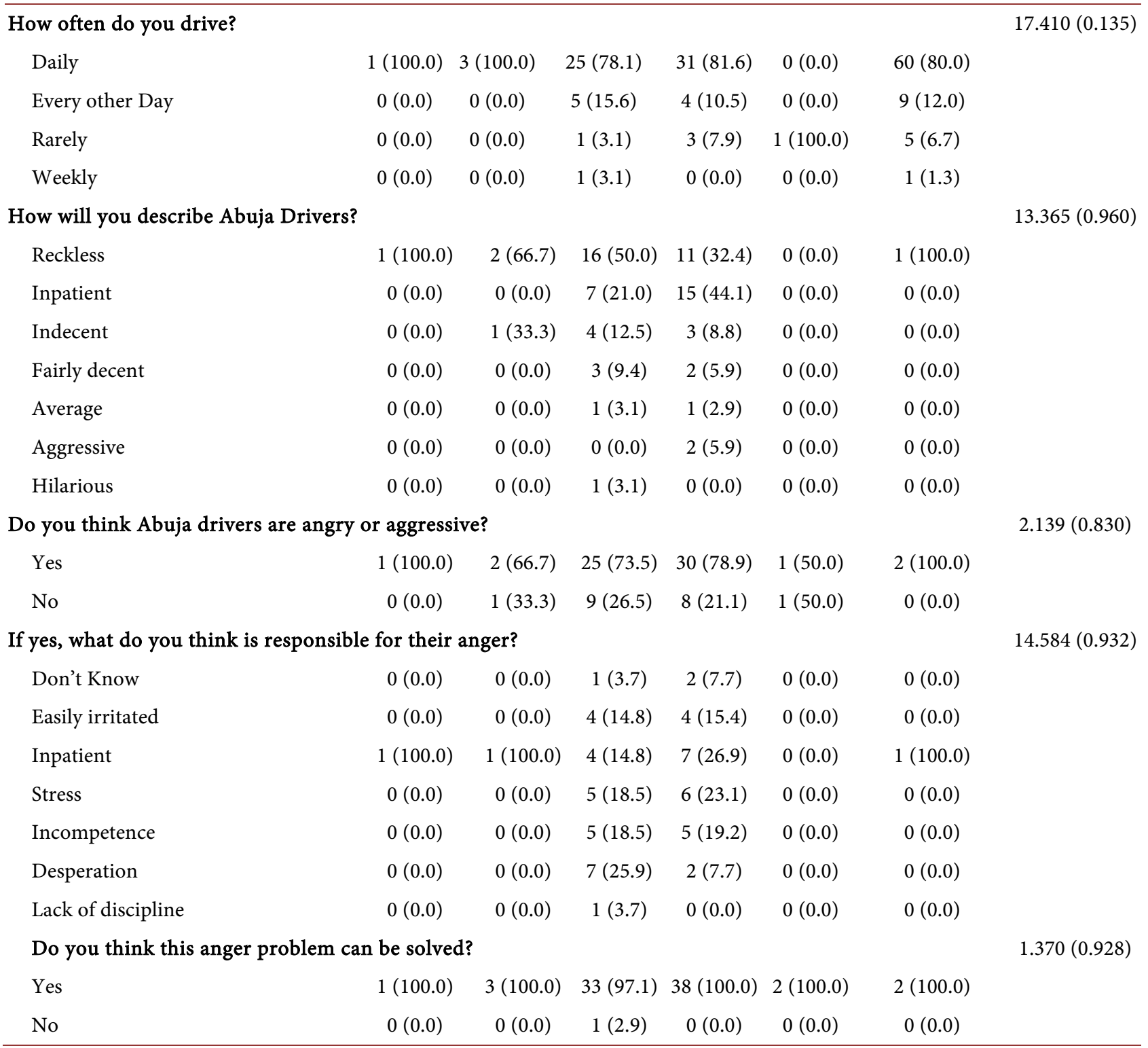

Table 3. Association between driving, and profession.

\begin{tabular}{|c|c|c|c|c|c|}
\hline \multirow{2}{*}{ Questions } & \multicolumn{4}{|c|}{ Profession } & \multirow{2}{*}{$\chi^{2}$ (sig) } \\
\hline & Private Sector & Public Sector & Entrepreneurs & Student & \\
\hline Can you drive? & & & & & $20.233(0.000)$ \\
\hline Yes & $21(100.0)$ & $31(93.9)$ & $22(95.7)$ & $1(33.3)$ & \\
\hline No & $0(0.0)$ & $2(6.10)$ & $1(4.3)$ & $2(66.6)$ & \\
\hline Driving Experience & & & & & $28.662(0.18)$ \\
\hline$<1$ & $0(0.0)$ & $0(0.0)$ & $1(4.5)$ & $0(0.0)$ & \\
\hline $1-5$ & $4(19.0)$ & $1(3.2)$ & $6(27.3)$ & $1(100.0)$ & \\
\hline $5-10$ & $9(42.9)$ & $9(29.0)$ & $5(22.7)$ & $0(0.0)$ & \\
\hline $11-15$ & $0(0.0)$ & $3(9.7)$ & $2(9.1)$ & $0(0.0)$ & \\
\hline
\end{tabular}


Continued

$\begin{array}{lcccc}16-20 & 3(14.3) & 7(22.6) & 3(13.6) & 0(0.0) \\ >20 & 5(23.8) & 11(35.5) & 1(4.5) & 0(0.0)\end{array}$

Total

How did you learn how to drive?

$10.090(0.608)$

How will you describe Abuja Drivers?
Family member

Driving School

Self-taught

A friend

Driver

Total

Daily

Every other Day

Rarely

Weekly

\section{Reckless}

Inpatient

Indecent

Fairly decent

Average

Aggressive

Hilarious
How often do you drive?

$4(19.0)$
$11(52.4)$
$4(19.0)$
$1(4.8)$
$1(4.8)$

$10(32.3)$

7 (22.6)

8 (25.8)

3 (9.7)

$3(9.7)$

$20(95.2)$
$1(4.8)$
$0(0.0)$
$0(0.0)$

$21(67.7)$

$10(47.6)$

6 (28.6)

2 (9.5)

3 (14.3)

$0(0.0)$

$0(0.0)$

$0(0.0)$

$12(44.8)$
$11(37.9)$
$3(10.3)$
$0(0.0)$
$0(0.0)$
$2(6.9)$
$0(0.0)$

26 (78.8)

$$
16(76.2)
$$

If yes, what do you think is responsible for their anger?

$\begin{array}{lc}\text { Don't Know } & 1(9.1) \\ \text { Easily irritated } & 1(9.1) \\ \text { Inpatient } & 3(27.3) \\ \text { Stress } & 2(18.2) \\ \text { Incompetence } & 1(9.1) \\ \text { Desperation } & 3(27.3) \\ \text { Lack of discipline } & 0(0.0)\end{array}$

19 (86.4)

$3(13.6)$

$0(0.0)$

$0(0.0)$

$1(3.2)$

$7(35.0)$

$5(25.0)$

$3(15.0)$

$2(10.0)$

$2(10.0)$

$0(0.0)$

$1(5.0)$

7 (21.2)

$$
1 \text { (4.0) }
$$$$
4 \text { (16.0) }
$$$$
7 \text { (28.0) }
$$$$
6 \text { (24.0) }
$$$$
4 \text { (16.0) }
$$$$
3 \text { (12.0) }
$$$$
0(0.0)
$$

17 (73.9)

$6(26.1)$

2 (66.7)

1 (33.3)

$$
\begin{gathered}
0(0.0) \\
0(0.0) \\
1(100.0) \\
0(0.0)
\end{gathered}
$$

$17.098(0.516)$

0.339 (0.953)

$5.453(0.941)$

3 (5.4)

8 (14.3)

14 (25.0)

11 (19.6)

10 (17.9)

9 (16.1)

1 (1.8)<smiles>[Mg][Mg][Mg]</smiles>

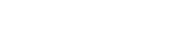

$22.791(0.007)$

Do you think this anger problem can be solved?

\begin{tabular}{ccccc} 
Yes & $21(100.0)$ & $32(97.0)$ & $23(100.0)$ & $3(100.0)$ \\
No & $0(0.0)$ & $1(3.0)$ & $0(0.0)$ & $0(0.0)$ \\
\hline
\end{tabular}


Participants linked drivers' aggression to impatience (17.5\%), stress (13.8\%), incompetence (12.5\%), desperation (11.3\%), lack of discipline (1.3\%) and irritation (10\%). The good news is that participants (98.8\%) think drivers' aggression could be remedied. The majority of the participants indicated that with the implementation of proper awareness and educational programs, strict traffic rules and proper coordination of road traffic in Abuja, drivers' anger will reduce to a wide margin.

\section{Discussion}

This study was carried out to determine the perception of the public on driver attitude on the road. The study leveraged a population that in itself partakes in the process of driving but not necessarily on permanents basis. The current study is in two facets: the first was to test the perception of the public to drivers' attitude in Abuja, the Federal Capital Territory; secondly to assess common behaviours in the driving population that have been linked to causes of crashes in literature.

The demographic characteristics of respondents indicates that females $(52.5 \%)$ were higher than their male counterparts (47.5\%). This result contradicts the majority of similar studies that report that males were higher than females (Ekpeyong et al., 2020; Uhegbu \& Tight, 2021). Ekpeyong et al. (2020) reported a marked difference between the males and female population in their study, indicating that males made up $88 \%$ of their study population. The gender distribution in the current study also varies from the report of Uhegbu and Tight (2021) who studying road user attitudes and their behaviour in Abuja indicated that males made up $66 \%$ of their total population. Although these studies were carried out in the same region, the disparity lied in the population targeted. Although the margin between males and females was not high, the result represents an observable picture of the study area where women are increasingly involved in driving. This is particularly evident in the rise of the number of females who are taxi drivers in Abuja, the Federal Capital Territory (Kadiri, 2017).

Analysis also indicates that the age group $31-40$ years $(50.0 \% ; n=40)$ had the highest number of participants. This is result paints a similar picture with the result of Uhegbu and Tight (2021) except that in the current study, the majority of drivers were between 31 - 40 years and in Uhegbu and Tight (2021) report, the majority of the drivers were in the age group of 41 - 50 years. However, the majority of the participants in the current study were in the age range of 31 - 50 years; similar to the age distribution of the population in the Uhegbu and Tight (2021) report. The age distribution in the current study also reflects the mean age reported by Ekpeyong et al. (2020) and the age bracket reported by Okafor et al. (2020).

The descriptive analysis of the level of education of the participants indicates that $1.3 \%$ had attained National Diploma (ND), 3.8\% attained Higher National Diploma (HND), 42.5\% attained Bachelor's Degree, $47.5 \%$ had attained Post 
Graduate Degrees, and 2.5\% were undergraduates while 2.5\% had obtained their Senior Secondary Certificate Examination (SSCE). This result shows that $95 \%$ of the respondents in the current study had attained a tertiary level of education. This result varies from the study of Onowhakpor et al. (2018) who reported that $89.2 \%$ of drivers in their study had attained a Secondary level of education. The disparity in these reports is attributed to the population studied; Onowhakpor et al. (2018) targeted intercity drivers.

A good number of respondents in the current study were either taught driving by a family member $(27.4 \%)$, self-taught $(17.5 \%)$, from friends $(6.3 \%)$, or from other drivers (8.8\%), implying that a greater number of respondents in the current study were not properly informed about driving ordinances. This could also show in driver attitudes, as well as cause or significantly contribute to factors that necessitate road collisions. Mayhew et al. (2017) agree that proper driver education can significantly reduce road accidents.

In the current study, the majority $(75 \%)$ of the respondents said that they drive daily. When one associates this daily act of driving with respondents' driving experience, one would expect crash rates to be very low. Other studies, however, have shown that driver attitude is only a subset of the causes of road accidents. This conclusion backs up the findings of Feng et al. (2017), who found that non-professional drivers had higher levels of anger than professional drivers. This is to demonstrate that drivers assessed in the current study, regardless of frequency of driving or driving experience, may exhibit higher levels of the attitude they attribute to professional drivers.

There was a significant association level of education and participant's ability to drive $(p<0.05)$; this is evident as $100 \%$ of the participants with OND, HND, and Postgraduate could drive; $94.1 \%$ of participants with Bachelor's degree could drive, $50 \%$ of undergraduate students could also drive whereas $100 \%$ of participants with SSCE could not drive. This result corroborates the age distribution of participants who indicated they can drive. It is also a reflection of the level of education attainable for the driving age in the country. However, the result varies distinctively from the report of Okafor et al. (2013) from the age distribution standpoint as well as the lack of significant association between level of education and level of driving knowledge.

Respondents in the current study described Abuja drivers' attitude to range from reckless to hilarious. $38.8 \%$ of the respondents indicated that Abuja drivers are mostly reckless, $27.5 \%$ believe that they are just inpatient, $10 \%$ indicated that they are indecent, $2.5 \%$ said Abuja drivers are aggressive, $6.3 \%$ indicated that Abuja drivers are fairly decent and $1.3 \%$ think they are hilarious. Participants indicated that these attitudes could come from driver's aggression (76.3\%). The participants' description of drivers' attitude reflects their perception of drivers within the study area. This result corroborates the report of Arthur (2015) who identified alcoholism, distraction, fatigue and speed as behavioural factors causing the increasing rate of road traffic crashes. The similarity is evident in the 
ability of participants to link increasing drivers' aggression to impatience, stress, incompetence, desperation, lack of discipline and irritation. The good news is that participants (98.8\%) think drivers' aggression could be remedied. A meta-analysis carried out by Zhang and Chan (2016) showed that driving anger significantly predicted all three types of aberrant driving; aggressive driving, risky driving and driving errors, respectively.

\section{Conclusion}

This study was able to identify rage as one of the key contributors to attitudinal adjustment in drivers, so establishing a relation between driver attitude and road traffic accidents. Impatience, stress, incompetence, desperation, lack of discipline, and irritability were also recognized as important indications of driver overall attitudinal difficulties in the research area.

\section{Recommendation}

- It is recommended that interventions such as driver education and re-education before driver license issue and renewal should be implemented to improve emotional control.

- Non-professional as well as professional drivers should receive regular emotional management training as part of their license renewal program and as part of a driver-passenger safety plan.

\section{Conflicts of Interest}

The authors declare no conflicts of interest regarding the publication of this paper.

\section{References}

Abdu, R., Shinar, D., \& Meiran, N. (2012). Situational (State) Anger and Driving. Transportation Research Part F: Traffic Psychology and Behaviour, 15, 575-580. https://doi.org/10.1016/j.trf.2012.05.007

Arthur, N. (2015). A Survey of Commercial Drivers' Perception on the Causes of Road Traffic Accidents in Nigeria. Journal of Medicine in the Tropics, 17, 12-15. https://doi.org/10.4103/2276-7096.148563

Berdoulat, E., Vavassori, D., \& Sastre, M. T. M. (2013). Driving Anger, Emotional and Instrumental Aggressiveness, and Impulsiveness in the Prediction of Aggressive and Transgressive Driving. Accident Analysis \& Prevention, 50, 758-767. https://doi.org/10.1016/j.aap.2012.06.029

Eiksund, S. (2009). A Geographical Perspective on Driving Attitudes and Behaviour among Young Adults in Urban and Rural Norway. Safety Science, 47, 529-536. https://doi.org/10.1016/j.ssci.2008.07.034

Ekpeyong, B. N., Echendu, D., \& Ekanem, E. (2020). Visual Health Status and Its Relationship with Road Traffic Accidents amongst Nigerian Vehicle Drivers: A Publication of the Nigerian Optometric Association. African Vision and Eye Health, 79, 8 p.

Evans, J. S. B. (2008). Dual-Processing Accounts of Reasoning, Judgment, and Social Cognition. Annual Review of Psychology, 59, 255-278. 
https://doi.org/10.1146/annurev.psych.59.103006.093629

Federal Government of Nigeria Official Gazette (2007). Nigeria Electricity Regulatory Commission's Meter Reading, Billing, Cash Collection and Credit Management for Electricity Supplies Regulations.

Federal Road Safety Corps (FRSC) (2017). Annual Report 2016. https://frsc.gov.ng/wp-content/uploads/2018/09/AnnualReport2017.pdf

Feng, Z., Yang, M., Ma, C., Lei, Y., Huang, W., Huang, Z., Zhan, J., \& Zhou M. (2017). Driving Anger and Its Relationships with Type a Behavior Patterns and Trait Anger: Differences between Professional and Non-Professional Drivers. PLoS ONE, 12, e0189793. https://doi.org/10.1371/journal.pone.0189793

Gonzalez-Iglesias, B., Gomez-Fraguela, J. A., \& Luengo-Martín, M. A. (2012). Driving Anger and Traffic Violations: Gender Differences. Transportation Research Part F: Traffic Psychology and Behaviour, 15, 404-412. https://doi.org/10.1016/j.trf.2012.03.002

Gudaji, M. I., \& Dankishiya, F. S. (2016). Relationship between Road Traffic Law Violation, Accident and Psychoactive Substance Use among Commercial Motorcycle Operators in Kano, Northwestern Nigeria. International Journal of Medicine and Medical Sciences, 8, 15-21.

International Transport Forum (2020). First African Observatory to Tackle the Continent's Road Safety Crisis.

https://www.roadsafety2030.com/news/first-african-observatory-to-tackle-the-contine nt-s-road-safety-crisis

Kadiri, F. (2017). World of Abuja Female Taxi Drivers. The Point. https://www.thepointng.com/world-of-abuja-female-taxi-drivers

Mayhew, D., Vanlaar, W., Lonero, L., Robertson, R., Marcoux, K., Wood, K., Clinton, K., \& Simpson, H. (2017). Evaluation of Beginner Driver Education in Oregon. Safety, 3, Article No. 9. https://doi.org/10.3390/safety3010009

Odufuwa, B. O., Salisu, U. O., \& Fasina, S. O. (2017). Determinants of Household Vehicle Acquisition and Use in a South-Western City of Nigeria. Transport \& Logistics: The International Journal, 17, 50-61.

Okafor, I., Odeyemi, K. A., \& Dolapo, D. (2013). Knowledge of Commercial Bus Drivers about Road Safety Measures in Lagos, Nigeria. Annals of African Medicine, 12, 34-39. https://doi.org/10.4103/1596-3519.108248

Okafor, K. C., Awunor, N. S., Otabor-Olubor, O., \& Okojie, O. H. (2020). Assesment of Visual Acuity of Commercial Long Distance Drivers in Benin City Edo State. Delta Journal of Ophthalmology, 21, 57-63.

Onowhakpor, A. O., Aikoriogie, O. L., Esene, H., Efegoma, Y. C., \& Okojie, O. H. (2018). Fitness to Drive among Commercial Intercity Drivers in Benin-City, Edo State. Journal of Community Medicine and Primary Healthcare, 30, 77-85.

Qu, W., Ge, Y., Jiang, C., Du, F., \& Zhang, K. (2014). The Dula Dangerous Driving Index in China: An Investigation of Reliability and Validity. Accident Analysis \& Prevention, 64, 62-68. https://doi.org/10.1016/j.aap.2013.11.004

Schimmack, U., \& Derryberry, D. (2008) Attentional Interference Effects of Emotional Pictures: Threat, Negativity, or Arousal. Emotion, 5, 55-66.

https://doi.org/10.1037/1528-3542.5.1.55

Uhegbu, U. N., \& Tight, M. R. (2021). Road Users' Attitude and Their Reported Behaviours in Abuja, Nigeria. Sustainability, 13, Article No. 4222.

https://doi.org/10.3390/su13084222 
Ukoji, V. (2014). Trends and Patterns of Fatal Road Accidents in Nigeria (2006-2014). French Institute for Research in Africa (IFRA-Nigeria).

World Health Organization (2015). Global Status Report on Road Safety 2015. https://www.who.int/violence injury prevention/road safety status/2015/en/

World Health Organization (2015). Road Traffic Injuries. https://www.who.int/news-room/fact-sheets/detail/road-traffic-injuries

Zhang, T., \& Chan, H. S. (2016). The Association between Driving Anger and Driving Outcomes: A Meta-Analysis of Evidence from the Past Twenty Years. Accident Analysis \& Prevention, 90, 50-62. https://doi.org/10.1016/j.aap.2016.02.009

Zhang, T., Chan, A. H., \& Zhang W. (2015). Dimensions of Driving Anger and Their Relationships with Aberrant Driving. Accident Analysis \& Prevention, 81, 124-133.

https://doi.org/10.1016/j.aap.2015.05.005 